\title{
The prevalence, clinical relevance and origin of autoantibodies in patients with Common variable immunodeficiency on regular immunoglobulin replacement therapy - the results from a prospective observational study
}

Tomas Milota ( $\nabla$ tomas.milota@fnmotol.cz)

Motol University Hospital and 2nd Faculty of Medicine, Charles University https://orcid.org/0000-00032105-3462

\section{Kotaska Karel}

Charles University and Motol University Hospital

\section{Lastuvka Petr}

Charles University and Motol University Hospital

\section{Smetanova Jitka}

Charles University and Motol University Hospital

\section{Bloomfield Marketa}

Charles University and Motol University Hospital

\section{Zachova Radana}

Charles University and Motol University Hospital

\section{Klojdova Iveta}

University of Chemistry and Technology, Prague

\section{Horvath Rudolf}

University Hospital Motol

\section{Sediva Anna}

Charles University and Motol University Hospital

\section{Research Article}

Keywords: Common variable immunodeficiency, Autoantibodies, Immunoglobulin replacement therapy, anti-GAD, anti-TPO

Posted Date: March 13th, 2021

DOI: https://doi.org/10.21203/rs.3.rs-286769/v1 
License: (c) (i) This work is licensed under a Creative Commons Attribution 4.0 International License. Read Full License 


\section{Abstract}

Background: Common variable immunodeficiency (CVID) is an inborn error of immunity characterized by disturbed immunoglobulin production. Despite of the terrain with severe antibody deficiency, autoantibody-mediated autoimmune phenomena belong to the most frequent autoimmune manifestation. However, many unresolved issues such as prevalence, clinical relevance and origin of autoantibodies detected in CVID patients receiving immunoglobulin replacement therapy (IRT) make the diagnostics of autoimmune complications difficult.

Methods: A prospective observational study evaluating the spectrum of 23 different autoantibodies in 38 CVID patients receiving IRT, and in the immunoglobulin solutions used for IRT.

Results: The study reveals a high prevalence of anti-GAD (55.3\%) and anti-TPO (68.4\%) autoantibodes in the cohort of $38 \mathrm{CVID}$ patients on regular IRT. However, the titers of anti-GAD (3.22 vs. $22 \mathrm{kU} / \mathrm{L}, \mathrm{p} \leq 0.0001)$ and anti-TPO (109.7 vs. $713 \mathrm{kU} / \mathrm{L}, \mathrm{P} \leq 0.0001)$ were significantly lower compared to the newly diagnosed T1D and AIT patients. Moreover, none of the CVID patients with detectable antibodies manifested with T1D and only three patients became suspected of having AIT. A high quantity of anti-GAD (3.24-24.48 $\mathrm{kU} / \mathrm{L})$ and anti-TPO (123.6-156.55 kU/L) autoantibodies was found in immunoglobulin solutions for IRT.

Conclusions: The study finds a very high prevalence of anti-GAD and anti-TPO autoantibodies in CVID patients receiving regular IRT. Nevertheless, the presence of anti-GAD and anti-TPO is not associated with the manifestation of the respective autoimmune disease. As the high titers of both anti-GAD and anti-TPO were also found in the therapeutics used for IRT, we suggest that the therapeutic immunoglobulins are the source of this false positivity.

\section{Introduction}

Common variable immunodeficiency disorder (CVID) is one of the most frequent inborn error of immunity with estimated prevalence $0.6-3.8$ / 100000 in European coutries (1). It is characterized by decreased immunoglobulin production, impaired specific antibody response and higher susceptibility to infections along with immune system dysregulation and higher prevalence of non-infectious complications, including a broad spectrum of autoimmune, lymphoproliferative and granulomatous manifestations (24), which significantly contribute to the morbidity and mortality of CVID patients $(5,6)$. A recent metaanalysis showed the pooled prevalence of autoimmunity is $29.8 \%$ in CVID (ranging from $13.6 \%$ to $54.1 \%)(7)$. Despite the markedly impaired antibody production, diseases hallmarked by the presence of autoantibodies, such as Autoimmune hemolytic anemia (AlHA) or Immune thrombocytopenic purpura (ITP), are amongst the most commonly diagnosed autoimmune complications in CVID patients, found in up to $38.9 \%$ of patients $(7,8)$. An increased prevalence of other autoimmune diseases associated with the tissue specific autoantibodies in comparison to general population was also reported, such as Autoimmune thyroiditis (AIT) or Type 1 diabetes (T1D) revealed in $0.8-8.7 \%$, and $0.8-7.1 \%$ of CVID patients respectively $(7,9,10)$. The mainstay of CVID management is a regular, long-term 
immunoglobulin replacement therapy (IRT). Importantly, the immunoglobulin solutions used for IRT were shown to contain various specific antibodies and may even be responsible for IRT associated adverse events such as self-limiting acute hemolysis triggered by pasivelly transmitted antierythrocyte alloantibodies (11). Therefore, we initiated a prospective observational trial to determine the prevalence, clinical significance and the origin of selected spectrum of autoantibodies in the sera of CVID patients.

\section{Methods}

This study was designed as a prospective observational trial and was approved by the Ethical Committee of Motol University Hospital. Only patients with signed informed consent and fulfilling inclusion criteria (1. ESID / ICON diagnostic criteria for CVID $(3,4)$, at least 3-month interval of follow up and exposition to the regular immunoglobulin replacement therapy) and exclusion criteria (previous exposition to the immunosupressive/corticosteroid therapy and/or the diagnosis of AIT or T1D) were enrolled and followed for up to 2 years.

The antibodies were detected in patients' sera using various laboratory methods including indirect immunofluorescence (ASP 1200, Werfen, Barcelona, Spain): anti-nuclear antibodies (ANA;Kallestad HEp-2 Cell Line Substrate Kit, Bio-Rad, Hercules, CA, USA)), double-stranded (ds) DNA (NOVA Lite dsDNA Crithidia luciliae Kit, Werfen, Barcelona, Spain); enzyme-linked immuno sorbent assay, ELISA (QUANTALyser 3000, Inova Diagnostics, San Diego, CA, USA): IgG rheumatoid factor - (RF; QUANTA Lite RF IgG, Werfen, Barcelona, Spain), anti-cardiolipin (ACLA; Anti-Cardiolipin IgG Kit, Orgentec, Chicago, IL, USA), anti-myeloperoxidase (MPO; Anti-MPO Kit, Orgentec, Chicago, IL, USA) , anti-proteinase 3 (PR3; Anti-PR3 Kit, Orgentec, Chicago, IL, USA), extractable nuclear antigens (ENAs, QUANTA Lite ENA 6 Kit, Werfen, Barcelona, Spain) - anti-Smith antigen (Sm), anti-ribonucleoprotein (RNP), anti-SS-A (Ro), anti-SS-B (La), anti-DNA topoisomerase I (Scl-70), anti-histidyl transfer RNA synthetase (Jo-1); chemiluminescent immunoassay (CLIA; Cobas e601, Roche, Mannheim, Germany ): anti-thyroid peroxidase (aTPO; AntiTPO Kit, Roche, Mannheim, Germany), anti-thyroglobulin (aTG; Anti-TG Kit, Roche, Mannheim, Germany); western blot (WB; D-tek, Mons, Belgium) - anti-F-actin, anti-soluble liver antigen (SLA), anti-liver/kidney microsome type 1 (LKM1), anti-liver cytosolic antigen type 1 (LC1), anti-mitochondrial M2 (AMAM2); radioimmunoassay (RIA; Berthold LB2111, Bad Wildbad, Germany ) - anti-glutamic acid decarboxylase (GAD; diagnostic kitMediPan, Berlin, Germany), anti-insulin (IAA; diagnostic kit MediPan, Berlin, Germany), anti-tyrosine phosphatase (IA2; diagnostic kit MediPan, Berlin, Germany). The same spectrum of autoantibodies was also asssessed in the immunoglobulin therapeutics used for IRT. All immunoglobulin solutions were diluted to $1 \%$ concentration equal to $10 \mathrm{~g} / \mathrm{L}$ before the analysis. The dilution was performed with $5 \%$ solution of bovine serum albumin (Bovine Serum Albumin lyophilized IgG-free powder, Merck, Darmstadt, Germany) and $0.09 \%$ solution of natrium chloride (Natrium Chloratum, Biotika Solutio Isotonica, Biotika, Prague, Czech Republic). Four immunoglobulin therapeutics administered to the enrolled patients for IRT were analyzed - 2 for intravenous administration (10\% IVIG - I, CSL Behring, Marburg, Germany; 10\% IVIG - II, Baxalta Innovations, Vienna, Austria) and 2 for subcutaneous administration (20\% SCIG, CSL Behring, Marburg, Germany; $16.5 \%$ SCIG Octapharma, 
Anderlecht, Belgium). Two different batches from each therapeutics were assessed, all the analyzed batches were also used for IRT in the enrolled patients.

Apart from the spectrum of autoantibodies the parameters of glucose and inzulin metabolism - fasting serum concentration of C-peptide (C-peptide Kit, Roche, Mannheim, Germany) measured by CLIA (Cobas e601, Roche, Mannheim, Germany) and glycosylated hemoglobin A1c (g-Hgb; Capillarys Hb A1c Kit, Sebia, France) using capillary electrophoresis(Capillarys 2 Analyzer, Sebia, France); thyroid gland function - free thyroxine (fT4; ADVIA Centaur FT4 assay), thyroid stimulating hormone (TSH; ADVIA Centaur FT4 assay) assessed by CLIA on ADVIA Centaur XPT Systems (Siemens, Tarrytown, NY). and thyroid gland ultrasonography (USG; Toshiba Nemio MX, Tokyo, Japan) were performed at screening and then in a year-long intervals and at the end of the study. Clinical follow-up visits were conducted in 3month intervals with IgG serum levels assessment using nephelometry (IMMAGE 800, Beckman Coulter, Indianapolis, IN, USA) and Human Serum IgG Kit (Beckman Coulter, Indianapolis, IN, USA).

The selected laboratory parameters were also compared to a cohort of 40 newly diagnosed T1D and 50 AIT patients.

Mean values and standard deviations (SD) were calculated. Two-Sample T test was used for unpaired parametric, Paired T test for paired parametric, and Kruskal-Wallis for multiple non-parametric data set. The differences were statistically significant when $p$ value was $\leq 0.05$ ). Statistical analysis was perfomed in Minitab, version 17.1 (Minitab Inc., State College, PA, USA).

\section{Results}

Baseline characteristics

Thirty-eight patients were enrolled, 22 females and 16 males, two patients with previously diagnosed Type 1 diabetes and 3 patients with Autoimmune thyroiditis were exluded at screening. The mean age at study initiation was 37.5 years (+/- 13.31 SD, range: 17-75), the mean time of disease duration 10 years (+/- 7.59, range: $0.25-28)$. Twelve patients were treated with IVIG and 26 patients with SCIG, the mean dose $300 \mathrm{mg} / \mathrm{kg} / \mathrm{month}$ (+/-59.6. range: $200-420)$. The dose of IRT remained unchanged during the duration of the entire study. The mean time of the participation in study was 2 years $(+/-0.64$, range: $0.25-$

2). There were no statistically significant differences in baseline characteristics between patient groups with negative and positive values of anti-GAD $(>0.9 \mathrm{kU} / \mathrm{mL})$ and anti-TPO $(>60 \mathrm{kU} / \mathrm{mL})$ autoantibodies respectively (Table 1 ).

The prevalence and clinical relevance of autoantibodies in CVID patients

Anti-TPO and anti-GAD autoantibodies markedly prevailed in the spectrum of assessed autoantibodies further including ANA (IgG), anti-dsDNA, anti-EMA (IgG), RF (IgG), ACLA (IgG), anti-F-actin, anti-SLA, antiLKM1, anti-LC1, anti-AMAM2, anti-MPO, anti-PR3, anti-Sm, anti-RNP, anti-SS-A, anti-SS-B, anti-Scl70, antiJo-1, anti-IAA, anti-IA2 and anti-TG. We identified $68.4 \%(n=26 / 38)$ of patients with positive values of anti- 
TPO and $55.3 \%(n=21 / 38)$ with positive values of anti-GAD autoantibodies in the cohort of CVID patients during the study. Both, anti-TPO and anti-GAD were present in $36.8 \%$ of patients $(n=14 / 38)$ Also, only $1 / 14(7 \%)$ and $12 / 20$ patietns (60\%) with anti-GAD and anti-TPO positivity, respectively, who were followed for $\geq 1$ year (the spectrum of autoantibodies assessed twice at least), remained positive for the entire study.

The mean titer of anti-GAD was $3.22 \mathrm{kU} / \mathrm{L}(+/-3.94)$ in CVID patients, which was significantly lower ( $\mathrm{p}$ $\leq 0.0001)$ compared to the levels of anti-GAD $22.0 \mathrm{kU} / \mathrm{L}(+/-26.1)$ in T1D at the time of the diagnosis (Figure 1). The presence of anti-GAD antibodies in CVID patients was not associated with a disturbed inzulin production or an impaired glucose metablism. The serum levels of C-peptide (891 pmol/L, +/601) were comparable to anti-GAD negative CVID patients ( $924 \mathrm{pmol} / \mathrm{L},+/-781, \mathrm{p}=0.177$ ). On the other hand, significant differences were found when C-peptide serum levels were compared to T1D patients (mean $266.8 \mathrm{pmol} / \mathrm{L},+/-235, \mathrm{p} \leq 0.0001$ ) (Figure 2). Similar results were also observed with serum levels of glycosylated hemoglobin A1c $(\mathrm{g}-\mathrm{Hgb})$, which were comparable between anti-GAD positive CVID patients $(32 \mathrm{mmol} / \mathrm{mol},+/-4.04)$ and negative patients $(32 \mathrm{mmol} / \mathrm{mol},+/-5.86, \mathrm{p}=0.65)$. Conversly, the levels of $\mathrm{g}-\mathrm{Hgb}$ were significantly higher in newly diagnosed T1D patients $(68 \mathrm{mmol} / \mathrm{mol}, \mathrm{SD} 33.06)$ than in anti-GAD positive CVID patients $(p \leq 0.0001)$. The serum concentrations of $C$-peptide as well as $g-H g b$ remained unchanged from the baseline to the end-of-study visit.

The mean titer of anti-TPO was $109.7 \mathrm{kU} / \mathrm{L}(+/-97.4)$, which was also significantly lower $(\mathrm{p} \leq 0.0001)$ in CVID patients compared to the mean levels of anti-TPO $713 \mathrm{kU} / \mathrm{L}(+/-520)$ in AIT patients (Figure 3). The serum concentrations of both TSH and fT4 in anti-TPO positive CVID patients (TSH: $2.08 \mathrm{mIU} / \mathrm{L},+/-1.17$, fT4: $14.49 \mathrm{pmol} / \mathrm{L},+/-1.53$ ) did not differ from the anti-TPO negative CVID patients (TSH: $1.67 \mathrm{mIU} / \mathrm{L},+/-$ $0.75, p=0.218$, fT4: $15.17,+/-3.47, p=0.518)$ and the concentration of TSH levels in anti-TPO positive CVID patients did not differ from the AIT patients $(1.40 \mathrm{mIU} / \mathrm{L},+/-3.11, p=0.826)$. The level of $\mathrm{fT} 4 \mathrm{in}$ anti-TPO positive CVID patients ( $14.49 \mathrm{pmol} / \mathrm{L},+/-1.53)$ was even significantly lower than in AIT group $(16.71,+/-2.57, \mathrm{p} \leq 0.0001)$. Nevertheless, the values were within normal ranges (11.50 - $22.70 \mathrm{pmol} / \mathrm{L})$. Neither TSH nor fT4 altered during the follow-up period. Moreover, insignificant differences $(p=0.593)$ were also observed in the proportion of ultrasonographic (USG) evidence of AIT. The USG diagnosis of AIT was considered in only three out of 26 anti-TPO positive CVID patients. On the other hand, one CVID patient probably developed AIT according to USG but no anti-TPO autoantibodies were detected.

The detection of autoantibodies in immunoglobulin therapeutics

The spectrum of autoantibodies including ANA, anti-dsDNA, anti-EMA, RF, ACLA, anti-F-actin, anti-SLA, anti-LKM1, anti-LC1, anti-AMAM2, anti-MPO, anti-PR3, anti-Sm, anti-RNP, anti-SS-A, anti-SS-B, anti-Scl70, anti-Jo-1, anti-IAA, anti-IA2 and anti-TG were not detected or were found to be below the lower limit of reference value (with the exception of anti-TG in SCIG-16.5 solution). In contrast, the anti-GAD and antiTPO were detected in very high levels in all the teste IRT. The titers of anti-GAD were fluctuating from 3.24 $\mathrm{kU} / \mathrm{L}(+/-1.51$, range: $0.9-4.74)$ in $10 \%$ IVIG-I to $24.48 \mathrm{kU} / \mathrm{L}(+/-13.94,12.45-40.54)$ in $10 \%$ IVIG-II and antiTPO from $123.6 \mathrm{kU} / \mathrm{L}(+/-7.43,114.30-138.20)$ in $16.5 \%$ SCIG to $156.55 \mathrm{kU} / \mathrm{L}(+/-19.62,108.70-165.40)$ 
$10 \%$ IVIG-I) (Table 2). Only the differences in the content of anti-GAD $(p<0.0001)$ between particular therapeutics were statistically significant (Supplementary Figure 4 and 5).

\section{Discussion}

CVID represents one of the most common primary antibody deficiency which is associated with a broad spectrum of non-infectious complications including various autoantibody-mediated autoimmune diseases. Several studies reported the presence of various antibodies directed against "self-antigens", such as feritin, thyreoglobulin or DNA in the therapeutics used for IRT (12). Antierythrocyte alloantibodies or anti-Ro (SS-A) were even associated with clinical manifestation - self-limiting hemolysis (11) and sicca syndrome (13). Thefore, we initiated the prospective observational study focusing on the prevalence, clinical significance and the origin of selected spectrum of autoantibodies in a cohort of 38 CVID patients treated with regular IRT.

Anti-GAD and anti-TPO were the most prevalent autoantibodies found in the majority of CVID patients on regular IRT (68.4\% and 55.3\%, respectively). All other investigated autoantibodies including ANA, antidsDNA, anti-EMA, RF, ACLA, anti-F-actin, anti-SLA, anti-LKM1, anti-LC1, anti-AMAM2, anti-MPO, anti-PR3, anti-Sm, anti-RNP, anti-SS-A, anti-SS-B, anti-Scl70, anti-Jo-1, anti-IAA, anti-IA2 and anti-TG were negative in all patients, with exception of anti-TG, anti-IAA and anti-IA2 found in patients with previously diagnosed T1D and AIT at the screening visit, who were excluded based on exclusion criteria. Interestingly, both excluded CVID patients with T1D were anti-GAD negative. However, the titers of anti-GAD observed in our cohort of CVID patients were significantly lower in comparison to newly diagnosed T1D patients. The cohort of CVID patients was prospectively followed to assess the T1D development. This included regular measurements of fasting C-peptide as a marker of inzulin production and g-Hgb reflecting long-term glycemia. No differences were found in serum concentration of C-peptide and g-Hgb between anti-GAD negative and positive CVID patients, as well as between the baseline and end-of-study visits in anti-GAD positive patients. On the other hand, the serum levels of C-peptide were significantly higher and the levels of g-Hgb significantly lower in comparison to newly diagnosed T1D patients suggesting an undisturbed inzulin production and glucose metabolism.

Similarly, the serum titers of anti-TPO autoantibodies in CVID patients were also significantly lower than in newly diagnosed AIT patients. However, no differences were found in the serum levels of TSH and fT4 between anti-TPO positive, anti-TPO negative CVID patients and AIT patients. Both paramters were within referential limits in all groups. Therefore, the thyroid gland USG was performed to evaluate the presence of predictive signs of subclinical AIT (14). Based on the USG, the diagnosis of AIT was considered in three out of 26 anti-TPO positive patients and in one patient without AIT specific autoantibodies.

The same spectrum of autoantibodies was also assessed in IRT therapeutics. Surprisingly, all solutions contained high amount of anti-GAD and anti-TPO autoantibodies. Other investigated autoantibodies were uniformly negative. The possible explanation for this phenomenon may be found in population-based studies investigating the prevalence of anti-GAD and anti-TPO. Anti-GAD autoantibodies were present in 
$0.9-1.7 \%$ of healthy donors, the highest prevalence $3.2 \%$ was observed in age group 30-34 years (15). Even higher prevalence was reported for anti-TPO antibodies - up to $31.7 \%$ of healthy donors $(16,17)$. Based on our findings and the previously published reports, we therefore suggest that these autoantibodies may be passively transfered into blood circulation via the immunoglobulin solutions. Our findings are also consistent with previous observations that T1D and AIT are predominantly T-cellmediated diseases (18-21). Correspondingly, both T1D and AIT may develop in the abscence of specific autoantibodies. The autoantibody negative cases comprise 3.5-19\% from all T1D patiens $(22,23)$, moreover, several seronegative T1D patients were also desribed amongst the CVID patients (10). Autoantibody negative AIT represents approximately $5 \%$ of all patients with AIT (24). While the tissue specific autoantibodies may not constitute the principal pathophysiological mechanisms in T1D and AIT, they represent a commonly used diagnostic and prognostic marker. The physicians should therefore be sensitized to the fact, that in CVID patients on regular immunoglobulin subtitution therapy neither serum anti-GAD nor anti-TPO are suitable tools for the screening or diagnosis of T1D or AIT.

The authors are aware, that due to the limitations of this pilot study, the results must be interpreted with caution. The strength of the study is particularly in its prospective design and the utilization of routine and certified laboratory methods. On the other, the limited number of included patients and the relatively short trial follow up time are its main limitations. Further multicentric and longer follow up studies are warranted to confirm these findings.

\section{Conclusions}

To our best knowledge, this is the first report investigating the content of broad spectrum of autoantibodies in therapeutics used for IRT and their clinical relevance. We identified high quantities of anti-GAD and anti-TPO autoantibodies in all investigated therapeutics that may be passively transfered to the patients' blood circulation.

Despite the fact that IRT may lead to autoantibody transfer, we found no evidence that this mechanism would contribute to the clinical manifestation of the autoimmune diseases, compromising the safety of IRT. However, it might interfere with the disease diagnosis. Based on our results, we recommend that antiGAD and anti-TPO should not be used for the screening or diagnosis of T1D and AIT in CVID patients on regular immunoglobulin subtitution therapy. Instead, the measurement of glycemia, C-peptide, $\mathrm{gHb}$ and thyroid ultrasound, respectivelly, may be the screening methods of choice.

\section{Declarations}

\section{Funding}

Grants of the Czech Health Research Council nr. NV18-05-00162 and the Technology Agency of the Czech Republic nr. TJ04000443. 


\section{Conflicts of Interest}

All authors declare no conflict of interest concerning this study and preparation of the manuscript.

\section{Availability of data and material}

N/A

\section{Code availability}

\section{N/A}

\section{Authors' Contribution}

TM (main author) made substantial contributions to conception and design of the study, analysis and interpretation of data, drafted the manusript

KK (co-author) made substantial contributions to conception and design of the study, acquisition of data, or analysis and interpretation of data

PL (co-author) made substantial contributions to conception and design of the study, acquisition of data, or analysis and interpretation of data

JS (co-author) made substantial contributions to conception and design of the study, acquisition of data, analysis and interpretation of data, drafted the article

MB (co-author) made substantial contributions to conception and design of the study, acquisition of data, analysis and interpretation of data, drafted the article

RZ (co-author) made substantial contributions to conception and design of the study, acquisition of data, analysis and interpretation of data

IK (co-author) made substantial contributions to conception and design of the study, acquisition of data, analysis and interpretation of data, drafted the article

$\mathrm{RH}$ (co-author) made substantial contributions to conception and design of the study, analysis and interpretation of data

AS (co-author) reviewed the manuscript critically for important intellectual content, gave final approval of the version to be published

\section{Ethics approval}

The study was approved by the Ethical Committee of Motol University Hospital.

\section{Consent to participate}


Only patients with signed informed consent approved by the Ethical Committee of Motol University Hospital.

\section{Consent for publication}

All co-authors have reviewed the manuscript and have agreed with the submission in the current form.

\section{Akcnowledgement}

The study was supported by the grant of the Czech Health Research Council nr. NV18-05-00162 and the Technology Agency of the Czech Republic nr. TJ04000443.

\section{References}

1. Selenius JS, Martelius T, Pikkarainen S, Siitonen S, Mattila E, Pietikainen R, et al. Unexpectedly High Prevalence of Common Variable Immunodeficiency in Finland. Frontiers in immunology. 2017;8:1190.

2. Ameratunga R, Brewerton $M$, Slade $C$, Jordan A, Gillis D, Steele R, et al. Comparison of diagnostic criteria for common variable immunodeficiency disorder. Frontiers in immunology. 2014;5:415.

3. Bonilla FA, Barlan I, Chapel H, Costa-Carvalho BT, Cunningham-Rundles C, de la Morena MT, et al. International Consensus Document (ICON): Common Variable Immunodeficiency Disorders. The journal of allergy and clinical immunology In practice. 2016;4(1):38-59.

4. Seidel MG, Kindle G, Gathmann B, Quinti I, Buckland M, van Montfrans J, et al. The European Society for Immunodeficiencies (ESID) Registry Working Definitions for the Clinical Diagnosis of Inborn Errors of Immunity. The journal of allergy and clinical immunology In practice. 2019;7(6):1763-70.

5. Ho HE, Cunningham-Rundles C. Non-infectious Complications of Common Variable Immunodeficiency: Updated Clinical Spectrum, Sequelae, and Insights to Pathogenesis. Frontiers in immunology. 2020;11:149.

6. Resnick ES, Moshier EL, Godbold JH, Cunningham-Rundles C. Morbidity and mortality in common variable immune deficiency over 4 decades. Blood. 2012;119(7):1650-7.

7. Rizvi FS, Zainaldain H, Rafiemanesh H, Jamee M, Hossein-Khannazer N, Hamedifar H, et al. Autoimmunity in common variable immunodeficiency: a systematic review and meta-analysis. Expert review of clinical immunology. 2020;16(12):1227-35.

8. Agarwal S, Cunningham-Rundles $\mathrm{C}$. Autoimmunity in common variable immunodeficiency. Annals of allergy, asthma \& immunology : official publication of the American College of Allergy, Asthma, \& Immunology. 2019;123(5):454-60.

9. Farmer JR, Ong MS, Barmettler S, Yonker LM, Fuleihan R, Sullivan KE, et al. Common Variable Immunodeficiency Non-Infectious Disease Endotypes Redefined Using Unbiased Network Clustering in Large Electronic Datasets. Frontiers in immunology. 2017;8:1740. 
10. Milota T, Sumnik Z, Obermannova B, Kralickova P, Vondrak K, Klocperk A, et al. Negativity for Specific Autoantibodies in Patients with Type 1 Diabetes That Developed on a Background of Common Variable Immunodeficiency. International archives of allergy and immunology. 2015;168(3):197-204.

11. Quinti I, Pulvirenti F, Milito C, Granata G, Giovannetti G, La Marra F, et al. Hemolysis in patients with antibody deficiencies on immunoglobulin replacement treatment. Transfusion. 2015;55(5):1067-74.

12. Lamoureux J, Aubin E, Lemieux R. Autoantibodies purified from therapeutic preparations of intravenous immunoglobulins (IVIg) induce the formation of autoimmune complexes in normal human serum: a role in the in vivo mechanisms of action of IVIg? International immunology. 2004;16(7):929-36.

13. van der Molen RG, Hamann D, Jacobs JF, van der Meer A, de Jong J, Kramer C, et al. Anti-SSA antibodies are present in immunoglobulin preparations. Transfusion. 2015;55(4):832-7.

14. Pedersen OM, Aardal NP, Larssen TB, Varhaug JE, Myking O, Vik-Mo H. The value of ultrasonography in predicting autoimmune thyroid disease. Thyroid : official journal of the American Thyroid Association. 2000;10(3):251-9.

15. Sorgjerd EP, Thorsby PM, Torjesen PA, Skorpen F, Kvaloy K, Grill V. Presence of anti-GAD in a nondiabetic population of adults; time dynamics and clinical influence: results from the HUNT study. BMJ open diabetes research \& care. 2015;3(1):e000076.

16. Amouzegar A, Gharibzadeh S, Kazemian E, Mehran L, Tohidi M, Azizi F. The Prevalence, Incidence and Natural Course of Positive Antithyroperoxidase Antibodies in a Population-Based Study: Tehran Thyroid Study. PloS one. 2017;12(1):e0169283.

17. Tipu HN, Ahmed D, Bashir MM, Asif N. Significance of Testing Anti-Thyroid Autoantibodies in Patients with Deranged Thyroid Profile. Journal of thyroid research. 2018;2018:9610497.

18. Ilonen J, Lempainen J, Veijola R. The heterogeneous pathogenesis of type 1 diabetes mellitus. Nature reviews Endocrinology. 2019;15(11):635-50.

19. Rydzewska M, Jaromin M, Pasierowska IE, Stozek K, Bossowski A. Role of the T and B lymphocytes in pathogenesis of autoimmune thyroid diseases. Thyroid research. 2018;11:2.

20. Taplin CE, Barker JM. Autoantibodies in type 1 diabetes. Autoimmunity. 2008;41(1):11-8.

21. Tomer $Y$, Huber $A$. The etiology of autoimmune thyroid disease: a story of genes and environment. Journal of autoimmunity. 2009;32(3-4):231-9.

22. Hameed S, Ellard S, Woodhead HJ, Neville KA, Walker JL, Craig ME, et al. Persistently autoantibody negative (PAN) type 1 diabetes mellitus in children. Pediatric diabetes. 2011;12(3 Pt 1):142-9.

23. Wang J, Miao D, Babu S, Yu J, Barker J, Klingensmith G, et al. Prevalence of autoantibody-negative diabetes is not rare at all ages and increases with older age and obesity. The Journal of clinical endocrinology and metabolism. 2007;92(1):88-92.

24. Rotondi M, de Martinis L, Coperchini F, Pignatti P, Pirali B, Ghilotti S, et al. Serum negative autoimmune thyroiditis displays a milder clinical picture compared with classic Hashimoto's thyroiditis. European journal of endocrinology. 2014;171(1):31-6. 


\section{Tables}

Table 1: Baseline characteristics of enrolled CVID patients, data shown for all patients (All) and patients with negative (-) vs. positive (+) values of anti-GAD $(>0.9 \mathrm{kU} / \mathrm{mL})$, anti-TPO $(>60 \mathrm{kU} / \mathrm{mL})$ autoantibodies respectively, medians (SD, maximu - minimum) are displayed, the differences between particular groups unsignificant $(p>0.05)$.

\begin{tabular}{|c|c|c|c|c|c|c|c|}
\hline Parameter & All & $\begin{array}{l}\text { Anti- } \\
\text { GAD- }\end{array}$ & $\begin{array}{l}\text { Anti- } \\
\text { GAD+ }\end{array}$ & $\begin{array}{c}\mathrm{p}- \\
\text { value }\end{array}$ & $\begin{array}{l}\text { Anti- } \\
\text { TPO- }\end{array}$ & $\begin{array}{l}\text { Anti- } \\
\text { TPO+ }\end{array}$ & $\begin{array}{c}\text { p- } \\
\text { value }\end{array}$ \\
\hline $\begin{array}{l}\text { Age at study initiation } \\
\text { (yrs.) }\end{array}$ & $\begin{array}{c}37.5 \\
(13.31,17- \\
75)\end{array}$ & $\begin{array}{c}41 \\
(10.5,31- \\
62)\end{array}$ & $\begin{array}{c}37 \\
(15.21,17- \\
75)\end{array}$ & 0.33 & $\begin{array}{c}34 \\
(15.88,17- \\
75)\end{array}$ & $\begin{array}{c}41.5 \\
(11.98,21- \\
64)\end{array}$ & 0.36 \\
\hline Disease duration (yrs.) & $\begin{array}{c}10 \\
(7.59 \\
0.25-28)\end{array}$ & $\begin{array}{c}11 \\
(7.14 \\
0.25-20)\end{array}$ & $\begin{array}{c}8 \\
(8.14 \\
0.25-28)\end{array}$ & 0.95 & $\begin{array}{c}4.5 \\
(6.8,0.25- \\
19)\end{array}$ & $\begin{array}{c}11 \\
(7.69 \\
0.25-28)\end{array}$ & 0.1 \\
\hline $\begin{array}{l}\text { Dose of IRT } \\
(\mathrm{mg} / \mathrm{kg} / \mathrm{month})\end{array}$ & $\begin{array}{c}300 \\
(59.2,250- \\
420)\end{array}$ & $\begin{array}{c}250 \\
(61.8,200- \\
420)\end{array}$ & $\begin{array}{c}310 \\
(54.5,200- \\
400)\end{array}$ & 0.14 & $\begin{array}{c}265 \\
(48.8,200- \\
370)\end{array}$ & $\begin{array}{c}300 \\
(61.5,200- \\
420)\end{array}$ & 0.12 \\
\hline $\begin{array}{l}\text { Time of study } \\
\text { participation (yrs.) }\end{array}$ & $\begin{array}{c}2 \\
(0.64 \\
0.25-2)\end{array}$ & $\begin{array}{c}2 \\
(0.67 \\
0.25-2)\end{array}$ & $\begin{array}{c}2 \\
(0.63, \\
0.25-2)\end{array}$ & 0.77 & $\begin{array}{c}1.5 \\
(0.72 \\
0.25-2)\end{array}$ & $\begin{array}{c}2 \\
(0.6,0.25- \\
2)\end{array}$ & 0.32 \\
\hline
\end{tabular}

Table 2: Spectrum of autoantibodes detected in human immunoglobulin (Ig) G therapeutics - $10 \%$ intravenous IgG (IVIG) - I, 10\% IVIG - II, 16.5\% and 20\% subcutaneous IgG (SCIG-16.5, SCIG-20), methods of detection - Indirect fluorescence (IF), Western blot (WB), Enzyme-Linked ImmunoSorbent Assay (ELISA), median values (SD, minimum - maximum), bold numbers indicating the values above the upper reference limit and reference intervals are displayed. 


\begin{tabular}{|c|c|c|c|c|c|c|}
\hline Parameter & Method & IVIG-I & IVIG-II & SCIG-16.5 & SCIG-20 & $\begin{array}{c}\text { Reference } \\
\text { intervals }\end{array}$ \\
\hline$\overline{\text { ANA }}$ & IF & $8 / 8$ negative & $8 / 8$ negative & $8 / 8$ negative & $8 / 8$ negative & $\begin{array}{l}\text { Negative - } \\
\text { positive }\end{array}$ \\
\hline Anti-dsDNA & IF & 8/8 negative & $8 / 8$ negative & 8/8 negative & $8 / 8$ negative & $\begin{array}{l}\text { Negative - } \\
\text { positive }\end{array}$ \\
\hline Anti-EMA & IF & 8/8 negative & 8/8 negative & 8/8 negative & 8/8 negative & $\begin{array}{l}\text { Negative - } \\
\text { positive }\end{array}$ \\
\hline Anti- F-actin & WB & $8 / 8$ negative & $8 / 8$ negative & 8/8 negative & $8 / 8$ negative & $\begin{array}{l}\text { Negative - } \\
\text { positive }\end{array}$ \\
\hline Anti- SLA & WB & 8/8 negative & 8/8 negative & 8/8 negative & 8/8 negative & $\begin{array}{l}\text { Negative - } \\
\text { positive }\end{array}$ \\
\hline Anti-LKM1 & WB & 8/8 negative & 8/8 negative & 8/8 negative & 8/8 negative & \begin{tabular}{|l}
$\begin{array}{l}\text { Negative - } \\
\text { positive }\end{array}$ \\
\end{tabular} \\
\hline Anti- LC1 & WB & 8/8 negative & $8 / 8$ negative & 8/8 negative & $8 / 8$ negative & $\begin{array}{l}\text { Negative - } \\
\text { positive }\end{array}$ \\
\hline Anti-AMAM2 & WB & 8/8 negative & 8/8 negative & 8/8 negative & 8/8 negative & $\begin{array}{l}\text { Negative - } \\
\text { positive }\end{array}$ \\
\hline $\mathrm{RF}$ & ELISA & $\begin{array}{l}3.66(2.51,2.74- \\
9.7)\end{array}$ & \begin{tabular}{|l|}
6.71 \\
$2.74-14.80)$
\end{tabular} & $\begin{array}{l}3.15(0.51,2.1- \\
3.5)\end{array}$ & \begin{tabular}{|l|}
$2.08(1.01$ \\
$0.900-2.98)$
\end{tabular} & $\begin{array}{l}0.0-22 \\
\mathrm{IU} / \mathrm{mL}\end{array}$ \\
\hline ACLA & ELISA & \begin{tabular}{|l}
$2.4(0.25,1.86-$ \\
$2.62)$
\end{tabular} & \begin{tabular}{|l}
$2.39(0.44$ \\
$1.7-2.84)$
\end{tabular} & $\begin{array}{l}2.06(0.085 \\
1.9-2.13)\end{array}$ & $\begin{array}{l}2.38(0.55,1.5- \\
3.15)\end{array}$ & $\begin{array}{l}0.0-10.0 \\
\text { GPL/mL }\end{array}$ \\
\hline Anti-MPO & ELISA & $\begin{array}{l}1.4(0.17,1.2- \\
1.7)\end{array}$ & $\begin{array}{l}1.45(0.23, \\
1.2-1.8)\end{array}$ & $\begin{array}{l}1.45(0.2,1.3- \\
1.8)\end{array}$ & $\begin{array}{l}1.50(0.22,1.2- \\
1.8)\end{array}$ & \begin{tabular}{|l|}
$0.0-5.0$ \\
$\mathrm{U} / \mathrm{mL}$
\end{tabular} \\
\hline Anti-PR3 & ELISA & $\begin{array}{l}1.80(0.16,1.5- \\
2.0)\end{array}$ & $\begin{array}{l}1.65(0.1,1.6- \\
1.9)\end{array}$ & $\begin{array}{l}1.70(0.2,1.5- \\
2.1)\end{array}$ & $\begin{array}{l}1.75(0.15,1.6- \\
2.0)\end{array}$ & $0.0-10 \mathrm{U} / \mathrm{mL}$ \\
\hline Anti-Sm & ELISA & $\begin{array}{l}0.08(0.01,0.07- \\
0.1)\end{array}$ & \begin{tabular}{|l}
$0.12(0.005$ \\
$0.11-0.12)$
\end{tabular} & $\begin{array}{l}0.09(0.01, \\
0.07-0.09)\end{array}$ & \begin{tabular}{|l}
$0.09(0.005$ \\
$0.08-0.09)$
\end{tabular} & $\begin{array}{l}0.0-1.20 \\
\text { index }\end{array}$ \\
\hline Anti-RNP & ELISA & $\begin{array}{l}0.16(0.04,0.15- \\
0.24)\end{array}$ & $\begin{array}{l}0.15(0.04, \\
0.14-0.22)\end{array}$ & $\begin{array}{l}0.14(0.12, \\
0.12-0.36)\end{array}$ & $\begin{array}{l}0.31(0.05,0.24- \\
0.36)\end{array}$ & $\begin{array}{l}0.0-1.20 \\
\text { index }\end{array}$ \\
\hline Anti-SS-A & ELISA & $\begin{array}{l}0.52(0.15,0.44- \\
0.77)\end{array}$ & $\begin{array}{l}0.72(0.03, \\
0.67-0.75)\end{array}$ & $\begin{array}{l}0.61(0.11, \\
0.46-0.7)\end{array}$ & $\begin{array}{l}0.68(0.19,0.41- \\
0.85)\end{array}$ & $\begin{array}{l}0.0-1.20 \\
\text { index }\end{array}$ \\
\hline Anti-SS-B & ELISA & $\begin{array}{l}0.18(0.03,0.16- \\
0.22)\end{array}$ & $\begin{array}{l}0.2(0.008, \\
0.19-0.21) \\
\end{array}$ & $\begin{array}{l}0.21(0.027 \\
0.18-0.24)\end{array}$ & $\begin{array}{l}0.19(0.02,0.17- \\
0.22)\end{array}$ & $\begin{array}{l}0.0-1.20 \\
\text { index }\end{array}$ \\
\hline Anti-Scl70 & ELISA & $\begin{array}{l}0.11(0.005,0.1- \\
0.11)\end{array}$ & \begin{tabular}{|l}
$0.16(0.006$ \\
$0.15-0.16)$
\end{tabular} & $\begin{array}{l}0.12(0.02,0.1- \\
0.13)\end{array}$ & $\begin{array}{l}0.13(0.01,0.11- \\
0.13)\end{array}$ & $\begin{array}{l}0.0-1.20 \\
\text { index }\end{array}$ \\
\hline Anti-Jo1 & ELISA & $\begin{array}{l}0.11(0.005,0.1- \\
0.11)\end{array}$ & \begin{tabular}{|l}
$0.11(0.006$, \\
$0.1-0.11)$
\end{tabular} & $\begin{array}{l}0.11(0.008, \\
0.1-0.12)\end{array}$ & $\begin{array}{l}0.11(0.01,0.11- \\
0.13)\end{array}$ & $\begin{array}{l}0.0-1.20 \\
\text { index }\end{array}$ \\
\hline Anti-GAD & RIA & $\begin{array}{l}24.48(13.94 \\
12.45-40.54)\end{array}$ & $\begin{array}{l}3.24(1.51, \\
0.9-4.74)\end{array}$ & $\begin{array}{l}7.28(3.80, \\
6.27-15.42)\end{array}$ & $\begin{array}{l}3.39(3.73,2.53- \\
11.19)\end{array}$ & $\begin{array}{l}0.0-0.90 \\
\mathrm{kU} / \mathrm{L}\end{array}$ \\
\hline Anti-IAA & RIA & $0.2(0.0,0.2-0.2)$ & $\begin{array}{l}0.2(0.0,0.2- \\
0.2)\end{array}$ & $\begin{array}{l}0.2(0.0,0.2- \\
0.2)\end{array}$ & $0.2(0.0,0.2-0.2)$ & $\begin{array}{l}0.0-0.40 \\
\mathrm{U} / \mathrm{mL}\end{array}$ \\
\hline Anti-IA2 & RIA & $0.8(0.0,0.8-0.8)$ & $\begin{array}{l}0.8(0.0,0.8- \\
0.8)\end{array}$ & $\begin{array}{l}0.8(0.0,0.8- \\
0.8)\end{array}$ & $0.8(0.0,0.8-0.8)$ & $0.0-1.0 \mathrm{kU} / \mathrm{L}$ \\
\hline Anti-TPO & CMIA & $\begin{array}{l}156.55(19.62, \\
108.70-165.40)\end{array}$ & $\begin{array}{l}142(43.3, \\
48.9-159.3)\end{array}$ & $\begin{array}{l}123.6(7.43, \\
114.30-138.20)\end{array}$ & \begin{tabular}{|l|}
$145.4(16.96$, \\
$122.90-167.10)$
\end{tabular} & $\begin{array}{l}0.0-60.0 \\
\mathrm{kU} / \mathrm{L}\end{array}$ \\
\hline Anti-TG & CMIA & $\begin{array}{l}41.5(24.63 \\
15.00-71.00)\end{array}$ & \begin{tabular}{|l}
$33.8(18.47$ \\
$15.00-54.80)$
\end{tabular} & $\begin{array}{l}73.85(24.47, \\
26.50-91.90)\end{array}$ & \begin{tabular}{|l}
50.75 (15.73, \\
$38.50-83.20)$
\end{tabular} & $\begin{array}{l}0.0-60.0 \\
\mathrm{kU} / \mathrm{L}\end{array}$ \\
\hline
\end{tabular}

\section{Figures}


Figure 1

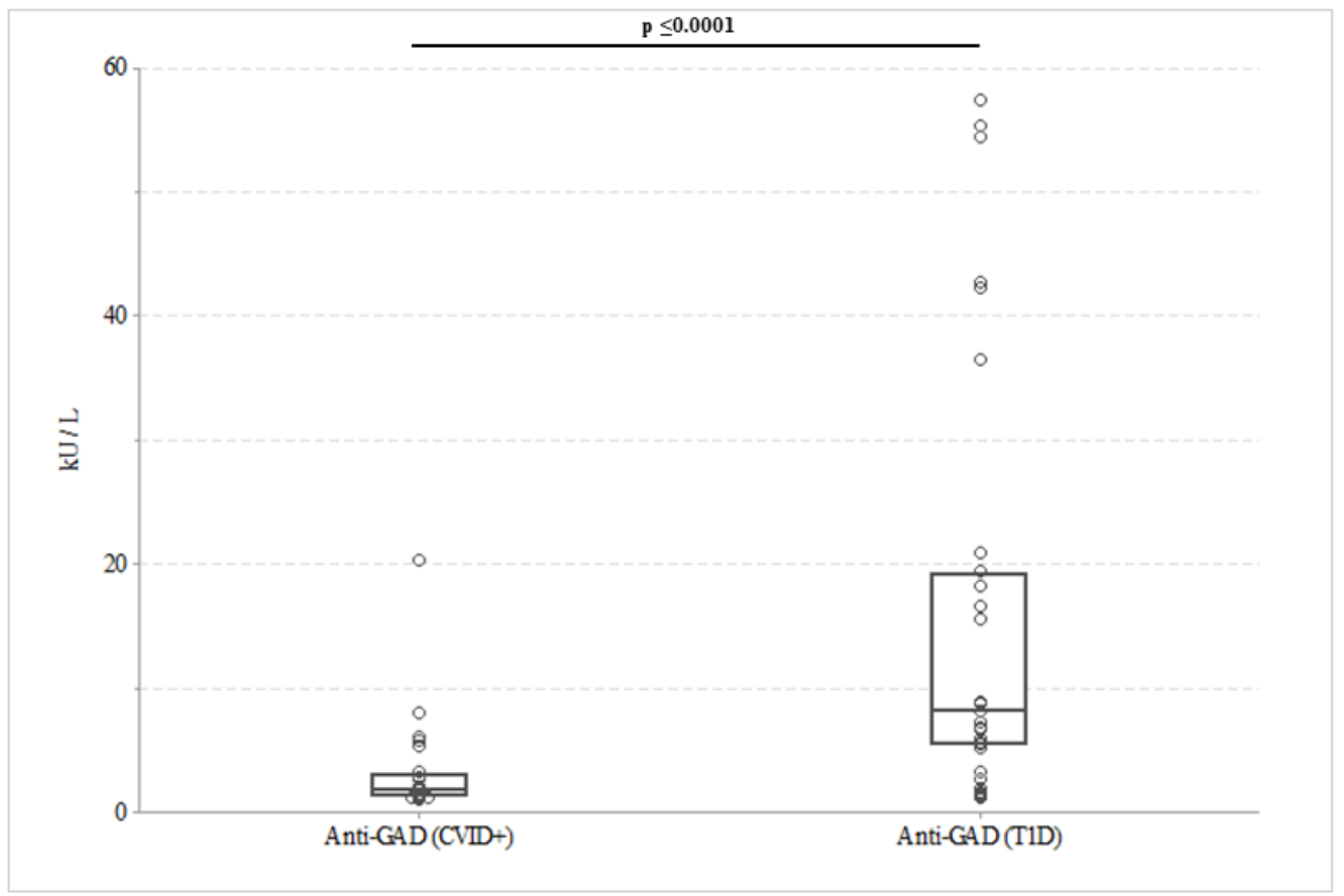

\section{Figure 1}

The serum levels (mean, 95\% confidence intervals and individual symbols) of anti-glutamic acid decarboxylase autoantibodies (Anti-GAD) in anti-GAD positive (>0.90 kU/L) Common variable immunodeficiency patients (CVID+) compared to newly diagnosed patients with Type 1 diabetes (T1D). 


\section{Figure 2}

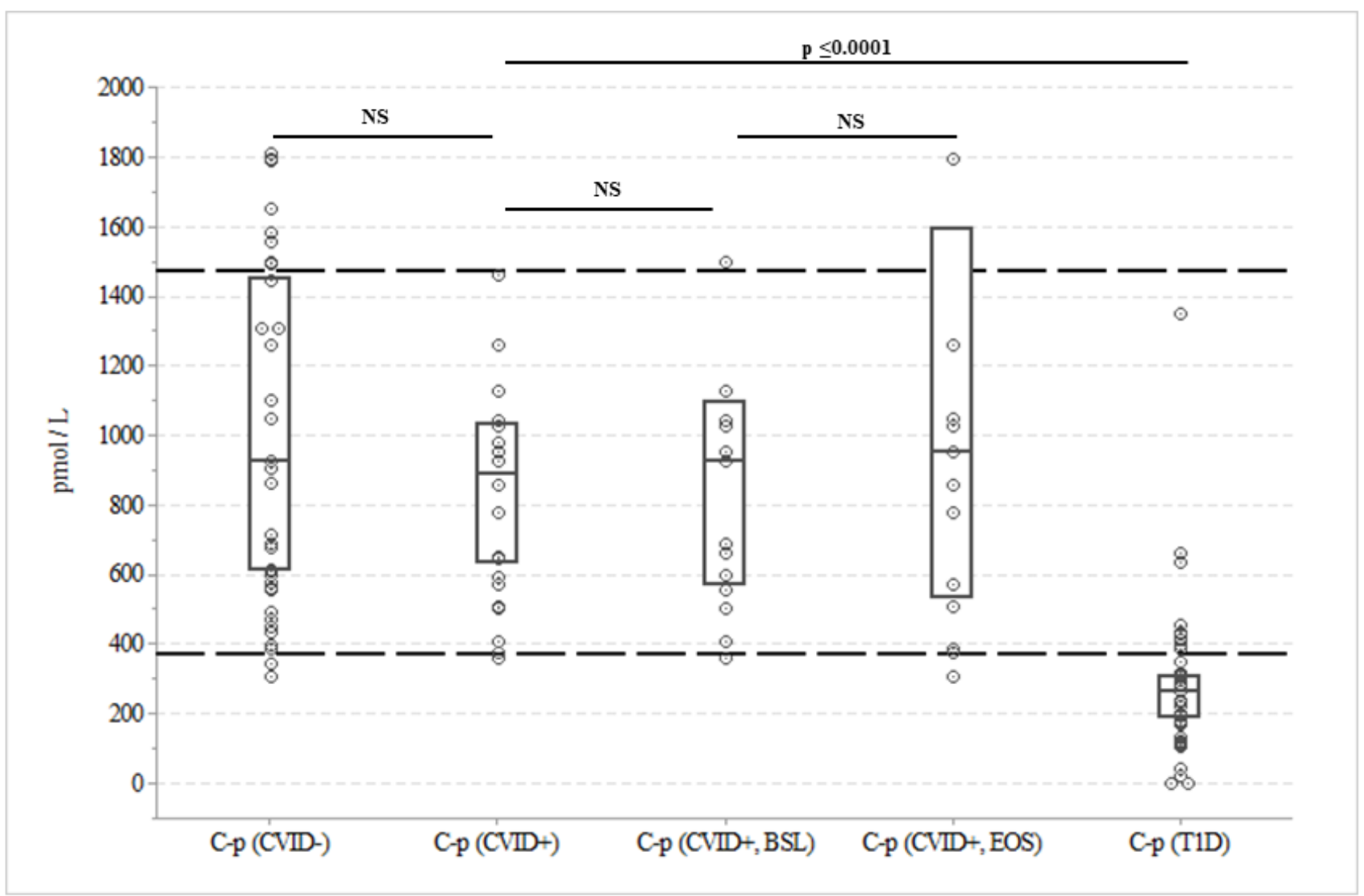

Figure 2

The serum concentration (mean, 95\% confidence intervals and individual symbols) of C-peptide (C-p) in anti-GAD negative (CVID-) and positive Common variable immunodeficiency patients (CVID+) and at baseline (BSL), end-of-study (EOS) visits compared to newly diagnosed patients with Type 1 diabetes (T1D) are displayed, upper (1470 pmol/L) and lower (370 pmol/L) reference limits indicated by bold gridlines. 


\section{Figure 3}

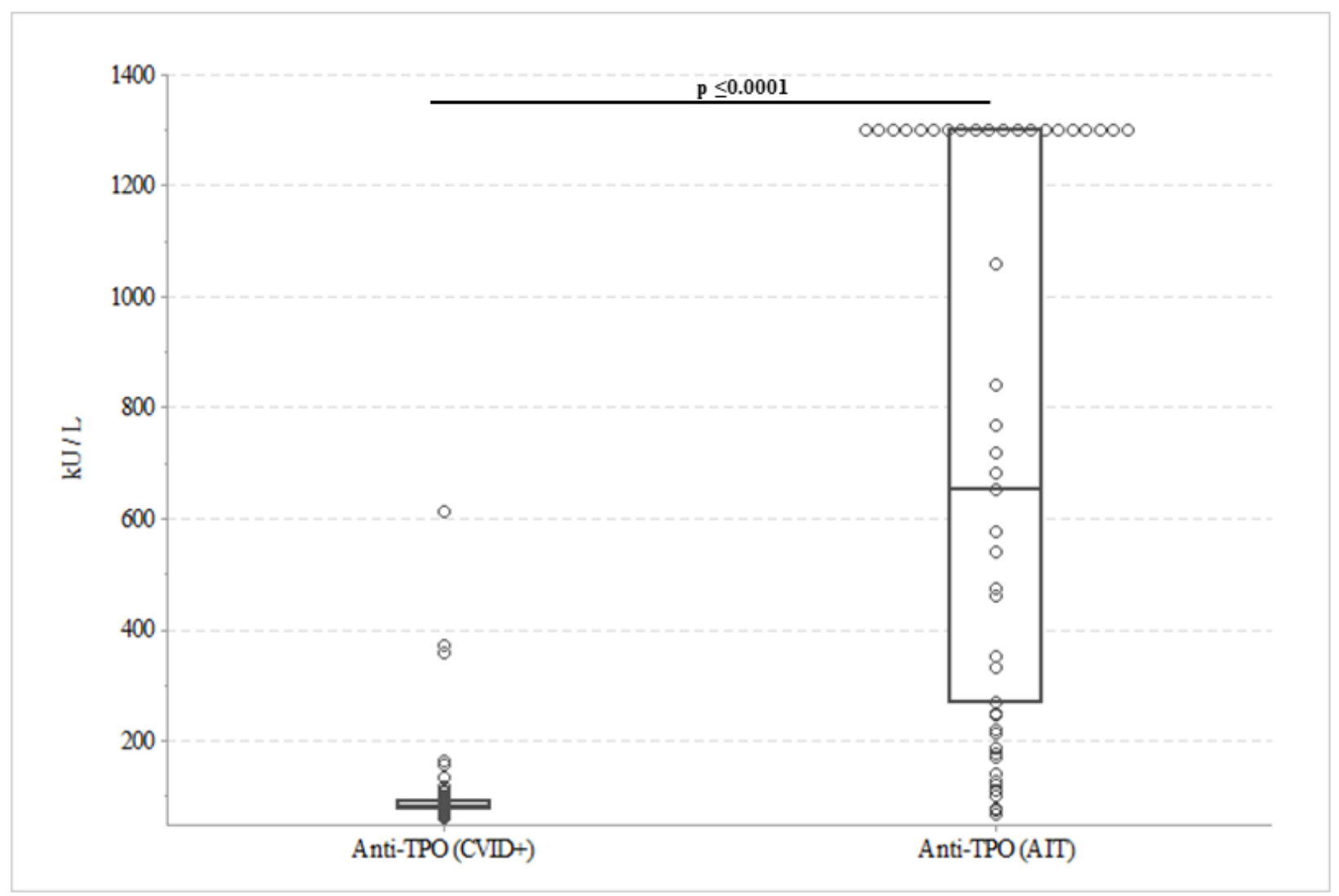

\section{Figure 3}

The serum levels (mean, 95\% confidence intervals and individual symbols) of anti-thyroid peroxidase autoantibodies (Anti-TPO) in anti-TPO positive (>0.60 kU/L) Common variable immunodeficiency patients (CVID+) compared to newly diagnosed patients with Autoimmune thyroiditis (AIT). 


\section{Figure 4}

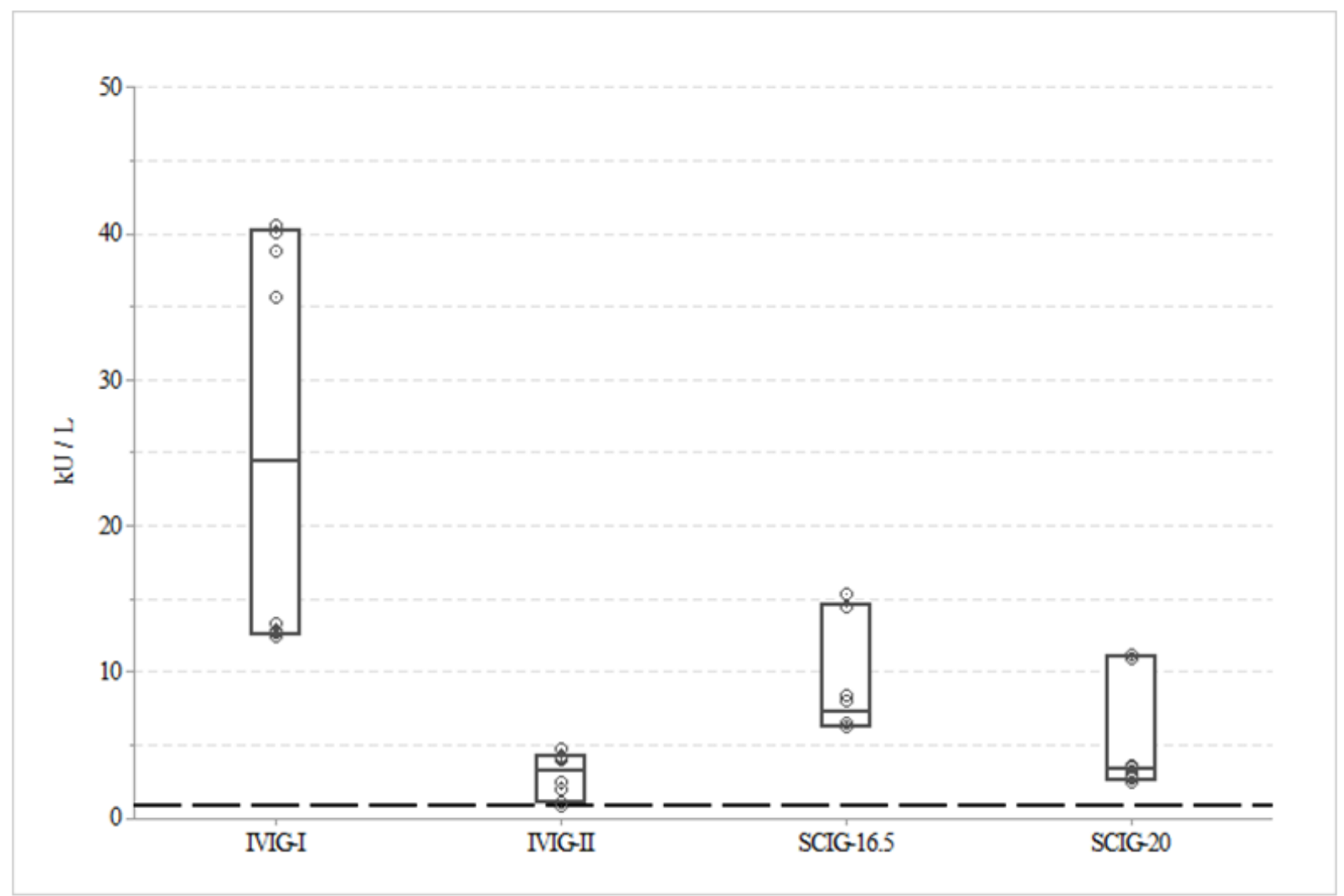

\section{Figure 4}

The concentration of of anti-glutamic acid decarboxylase (anti-GAD) autoantibodies (mean, 95\% confidence intervals and individual symbols) in different solutions for immunoglobulin replacement therapy ( $10 \%$ solution for intravenous use IVIG-I and IVIG II, $16.5 \%$ and $20 \%$ solutions for subcutaneous use SCIG-16.5 and SCIG-20), statistically significant differences ( $p \leq 0.0001)$, upper reference limit (0.9 $\mathrm{kU} / \mathrm{L}$ ) indicated by bold gridline. 


\section{Figure 5}

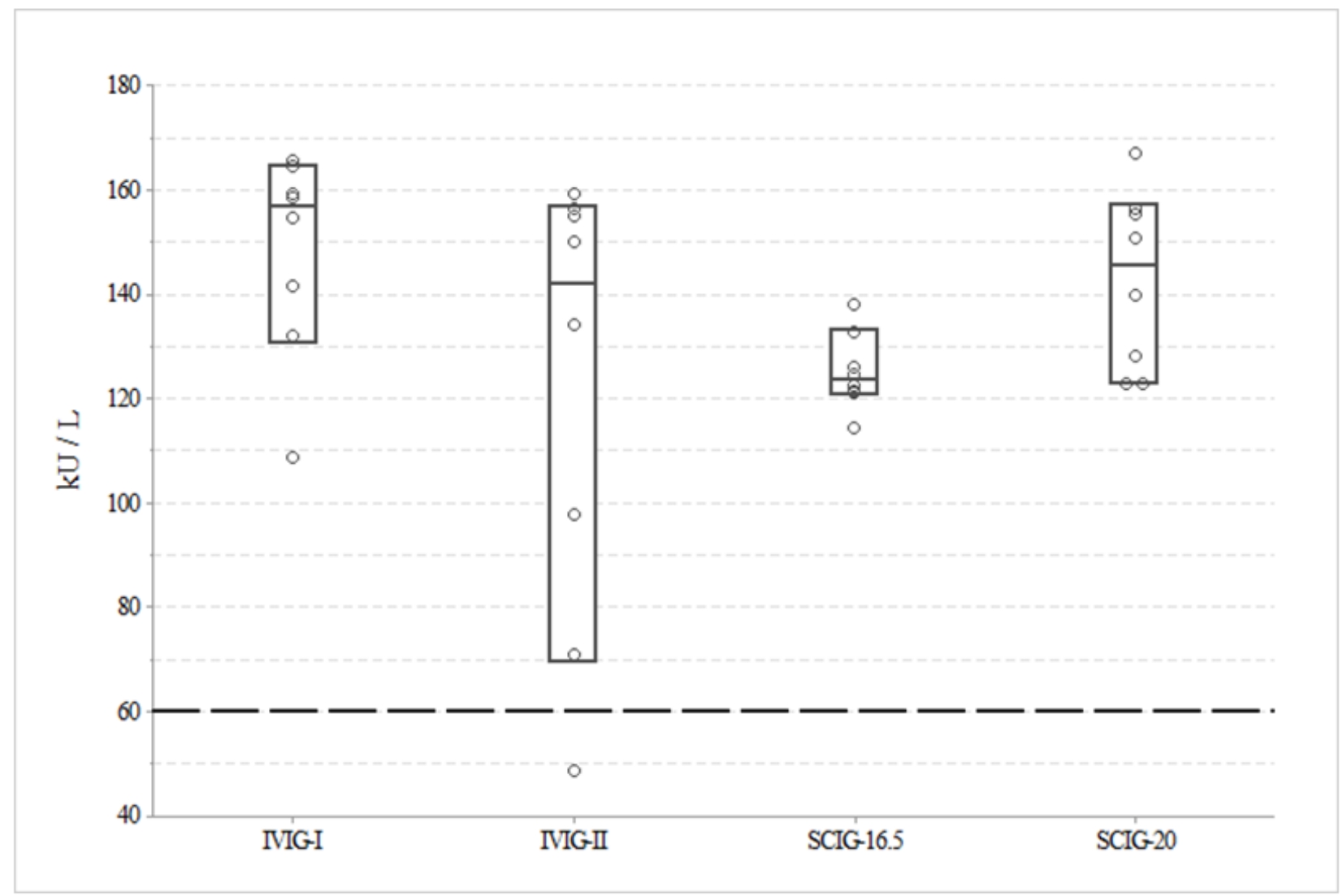

\section{Figure 5}

The concentration of anti-thyroid peroxidase autoantibodies (Anti-TPO) autoantibodies (mean, 95\% confidence intervals and individual symbols) in different solutions for immunoglobulin replacement therapy ( $10 \%$ solution for intravenous use IVIG-I and IVIG II, $16.5 \%$ and $20 \%$ solutions for subcutaneous use SCIG-16.5 and SCIG-20), differences statistically non-significant $(p=0.064)$, upper reference limit $(60.0 \mathrm{kU} / \mathrm{L})$ indicated by bold gridline. 